\title{
Multi-attribute decision making parametric optimization and modeling in hard turning using ceramic insert through grey relational analysis: A case study
}

\author{
Amlana Panda, Ashok Kumar Sahoo* and Arun Kumar Rout
}

School of Mechanical Engineering, KIIT University, Bhubaneswar-24, Odisha, India

\begin{tabular}{l}
\hline C H R O N I C L E \\
\hline Article history: \\
Received October 25, 2015 \\
Received in revised format: \\
February 12, 2016 \\
Accepted March 15, 2016 \\
Available online \\
March 162016 \\
\hline Keywords: \\
Grey relational analysis \\
Taguchi \\
Hard turning \\
Flank wear \\
Surface roughness
\end{tabular}

\section{Introduction}

The machining industries targeted basically the ease of metal removal named as machinability which can be assessed by several factors such as achievements of good surface quality, less tool wear, less damage to the machine tool, workpiece and cutting tool, less cutting temperature at the chip-tool interface, less cutting force and power consumption and economically viable and environmentally friendly. The challenges of machining hardened work materials with appropriate cutting tool materials and levels of process parameters is still a burning issue in manufacturing sectors because of pressing demand of surface quality and it adversely affected by evolution of tool wear. Therefore the optimized process parameter is essentially needed to overcome these challenging issues. Also the suitable predictive models thus required to predict the wear and surface roughness prior to machining of hardened materials. Hard turning now-a-days adopted in many machining industries due to its flexibility with respect to cost, time and environment compared to traditional grinding operations.

\footnotetext{
* Corresponding author.

E-mail address: aklala72@gmail.com (A. K. Sahoo)
}

(C) 2016 Growing Science Ltd. All rights reserved. doi: $10.5267 /$ j.dsl.2016.3.001 
Many researchers have undergone some research based on these aspects. Tzeng et al. (2009) applied grey relational analysis for optimization of parameters in CNC turning for SKD11 (JIS) using Taguchi orthogonal array. The depth of cut was found to be the most dominant influencing parameter on the roughness average and the cutting speed for roughness maximum and the roundness. Pal et al. (2009) adopted grey-based Taguchi method for optimization of pulsed metal inert gas welding process parameters. If the tensile strength as the most important quality parameter is assigned a higher weight, then the pulse voltage was found to be the most influential process parameter. Optimization results are finally validated.

Sahoo et al. (2013) obtained multi-response optimization of process parameters during machining of $\mathrm{Al} / \mathrm{SiCp} \mathrm{MMC}$ under dry environment. The model developed by regression approach has been found to be adequate and experimental and predicted values are very close to each other. Sahoo et al. (2013) developed flank wear model using RSM in turning hardened EN 24 steel with PVD TiN coated mixed ceramic insert under dry environment. The adequacy of model has been checked using correlation coefficients. Machining time is the most significant parameter on flank wear followed by cutting speed and feed. Bhuyan \& Routara (2016) optimized the process parameters during Electrical discharge machining of Al-18wt.\%SiCp metal matrix composite (MMC) through VIKOR and Entropy weight measurement approach. The result is validated by conformation test using the liner mathematical model.

Noorul Haq et al. (2008) utilized grey based orthogonal array method to optimize multi-responses in drilling $\mathrm{Al} / \mathrm{SiC}$ metal matrix composite and were greatly improved. Lin (2004) reported that the performance characteristics of the turning operations such as tool life, cutting force, and surface roughness were improved together by using the Taguchi method coupled with grey relational analysis. Chinchanikar \& S. K. Choudhury (2013) analyzed the wear behavior of uncoated, PVD coated singlelayer TiAlN and CVD multi-layer MT-TiCN $/ \mathrm{Al}_{2} \mathrm{O}_{3} / \mathrm{TiN}$ carbide inserts during turning of hardened AISI 4340 steel (35 HRC) under dry environment. Using coated tool, the limiting cutting speed increase from 62 to $200 \mathrm{~m} / \mathrm{min}$, which further extends up-to 300-350 $\mathrm{m} / \mathrm{min}$ when using multi-layer coating scheme. The dominant forms of wear mechanisms found were flank wear, crater wear and catastrophic failure.

Aggarwal et al. (2008) studied multi-response characteristics such as tool life, cutting force, surface roughness and power consumption during machining AISI P20 tool steel (32-36 HRC) with TiN coated carbide tool using principal component analysis (PCA). Nalbant et al. (2007) studied turning of AISI 1030 steel with TiN coated carbide insert using Taguchi $\mathrm{L}_{9}$ orthogonal array and optimized the process parameter. It is obtained that, greater insert radius; low feed rate and low depth of cut is suitable for lowering the surface roughness in turning. Noordin et al. (2004) investigated dry turning of AISI 1045 steel using multilayer coated carbide $\left(\mathrm{TiCN} / \mathrm{Al}_{2} \mathrm{O}_{3} / \mathrm{TiN}\right)$ insert through central composite design $(\mathrm{CCD})$ and response surface methodology (RSM). Feed is found to be most dominant parameter for surface roughness and tangential force. Das \& Chattopadhyay (2003) recommended AHP (Analytic Hierarchy Process) method to be good enough to evaluate tool wear in turning.

Choudhury and El-Baradie (1998) developed first and second-order tool-life models using response surface methodology in dry turning of high strength steel EN24 applying uncoated carbide tool. The cutting speed was the dominant parameter influencing tool wear, followed by the feed rate and the depth of cut. Davim (2001) applied Taguchi method for investigation on surface finish in turning using carbide tool established a correlation using multiple linear regression analysis. The results indicated that the cutting speed and interaction between cutting speed/feed had a greater influence on surface roughness followed be feed. Depth of cut did not have significance. Palanikumar (2008) discusses the use of Taguchi and response surface methodologies for minimizing the surface roughness in machining GFRP using PCD tool. Feed is found to be the most dominant parameter for surface roughness followed by cutting speed. Second order model reveals that the predicted values are very close to the measured value and can be safely used in the machining. Dey and Chakraborty (2016) studied the machinability 
characteristics of aluminium, copper and steel alloys using grey TOPSIS technique. The method seems easier for the manufacturers to select a particular alloy that can be easily machined. Sargade et al. (2016) investigated the influence of cutting parameters on surface roughness and cutting force in dry machining titanium alloy using PVD TiAlN coated tool through Taguchi orthogonal array. Linear and second order models have been developed. Feed rate is found to be most influencing parameter on responses. A good agreement between experimental and predicted values is obtained.

Natarajan (2006) adopted an evolutionary technique named particle swarm optimization instead of a back-propagation algorithm for optimization of tool life and it is proven that the experimental results matched well with the values predicted by both artificial neural network with back-propagation and the proposed method. It is found that the computational time is greatly reduced by this method. Saravanan (2003) utilized simulated annealing (SA) and genetic algorithm (GA) to optimize machining parameters for continuous profile machining with respect to the minimum production cost, subject to a set of practical constraints such as cutting force, power constraint and tool tip temperature. Davim et al. (2008) developed ANN model for surface roughness parameters to investigate the effects of cutting conditions during turning of free machining steel. The analysis reveals that cutting speed and feed rate have significant effects in reducing the surface roughness, while the depth of cut has the least effect. After going through the literature review, the present investigation is undertaken to make a decision on parametric optimization of multi-responses such as flank wear and surface roughness during machining hardened AISI 52100 steel $(55 \pm 1)$ steel using mixed ceramic insert under dry environment. Also predicted mathematical models of $1^{\text {st }}$ and $2^{\text {nd }}$ order have been developed for responses and checked for its accuracy.

\section{Experimentation and test results}

The machining experiment has been carried out taking bearing steel (AISI 52100) of $40 \mathrm{~mm}$ diameter with $120 \mathrm{~mm}$ length hardened to $55 \pm 1$ Rockwell in C scale (HRC). The tests are performed on CNC lathe (JobberXL, ACE) under dry cutting environment. The skin rust layer due to heat treatment has been removed by conducting some preliminary runs prior to final experiment. The commercially available negative mixed ceramic insert $\left(\mathrm{Al}_{2} \mathrm{O}_{3}+\mathrm{TiCN}\right)$ has been used in hard turning designated as CNGA 120408T02020 (WIDIA, CW2015) which is mounted on tool holder designated as PCLNR2525M12 (Fig.1).

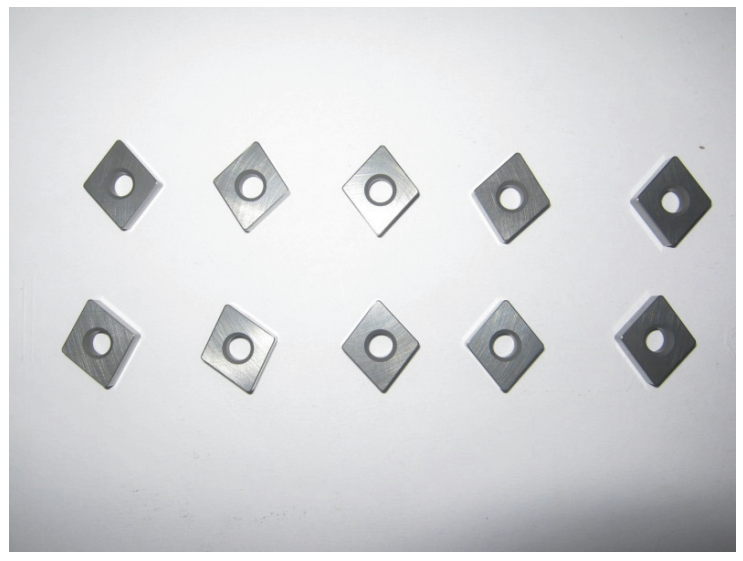

Fig.1. Mixed ceramic insert

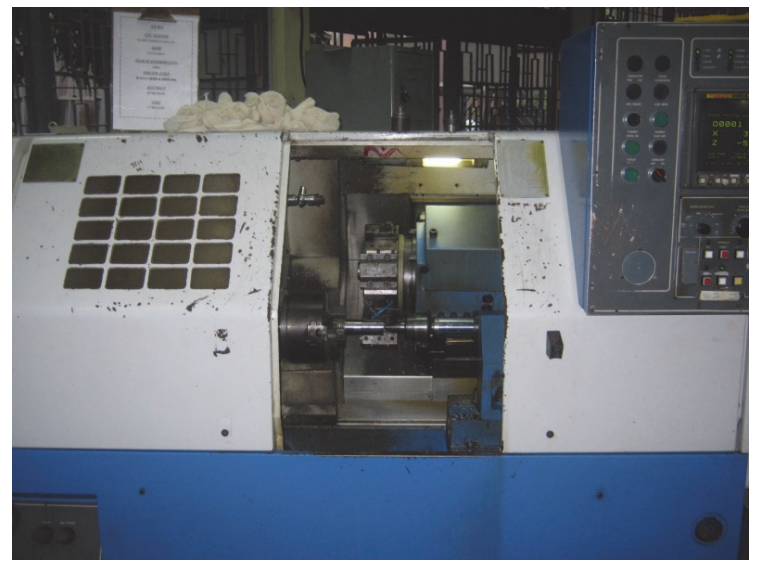

Fig. 2. Experimental setup

The arithmetic surface roughness average ( $\mathrm{Ra}$ ) and flank wear of insert (VBc) have been measured at each run through surface roughness tester (Taylor Hobson, Surtronic 25) and profile projector with stereo zoom microscope. Experiments are planned as per Taguchi $\mathrm{L}_{16}$ orthogonal array taking three factors (process parameters) such as cutting speed (v), feed (f) and depth of cut (d) at four levels. The level of cutting speed varies from $70 \mathrm{~m} / \mathrm{min}$ as level $1,110 \mathrm{~m} / \mathrm{min}$ as level $2,150 \mathrm{~m} / \mathrm{min}$ as level 3 and $180 \mathrm{~m} / \mathrm{min}$ as level 4. Similarly, the level of feed varies from 0.04 as level 1, 0.08 as level 2, 0.12 as 
level 3 and $0.16 \mathrm{~mm} / \mathrm{rev}$ as level 4 respectively. The ranges of depth of cut have been taken as 0.1 as level 1, 0.2 as level 2, 0.3 as level 3 and $0.4 \mathrm{~mm}$ as level 4 respectively. Taguchi $\mathrm{L}_{16}$ orthogonal array (OA) design constitutes total 16 experimental runs which are conducted on fresh cutting edge at each run and machining length of each experiment has been fixed as $100 \mathrm{~mm}$ (Fig.2). The experimental results of both flank wear and surface roughness are shown in Table 1.

\section{Table 1}

Experimental results for flank wear and surface roughness as per Taguchi $\mathrm{L}_{16} \mathrm{OA}$

\begin{tabular}{|c|c|c|c|c|c|}
\hline \multirow[t]{2}{*}{ Run No } & \multicolumn{3}{|c|}{ Process parameters } & \multicolumn{2}{|c|}{ Experimental results } \\
\hline & $\mathrm{d}$ & $\mathrm{f}$ & $\mathrm{V}$ & $\mathrm{VBc}$ & $\mathrm{Ra}$ \\
\hline 1 & 0.1 & 0.04 & 70 & 0.054 & 0.95 \\
\hline 2 & 0.1 & 0.08 & 110 & 0.066 & 0.31 \\
\hline 3 & 0.1 & 0.12 & 150 & 0.071 & 0.48 \\
\hline 4 & 0.1 & 0.16 & 190 & 0.092 & 1.05 \\
\hline 5 & 0.2 & 0.04 & 110 & 0.072 & 0.29 \\
\hline 6 & 0.2 & 0.08 & 70 & 0.058 & 0.45 \\
\hline 7 & 0.2 & 0.12 & 190 & 0.131 & 0.87 \\
\hline 8 & 0.2 & 0.16 & 150 & 0.119 & 1.15 \\
\hline 9 & 0.3 & 0.04 & 150 & 0.091 & 0.22 \\
\hline 10 & 0.3 & 0.08 & 190 & 0.143 & 0.61 \\
\hline 11 & 0.3 & 0.12 & 70 & 0.075 & 0.52 \\
\hline 12 & 0.3 & 0.16 & 110 & 0.104 & 1.02 \\
\hline 13 & 0.4 & 0.04 & 190 & 0.152 & 0.34 \\
\hline 14 & 0.4 & 0.08 & 150 & 0.12 & 0.41 \\
\hline 15 & 0.4 & 0.12 & 110 & 0.125 & 0.47 \\
\hline 16 & 0.4 & 0.16 & 70 & 0.112 & 1.23 \\
\hline
\end{tabular}

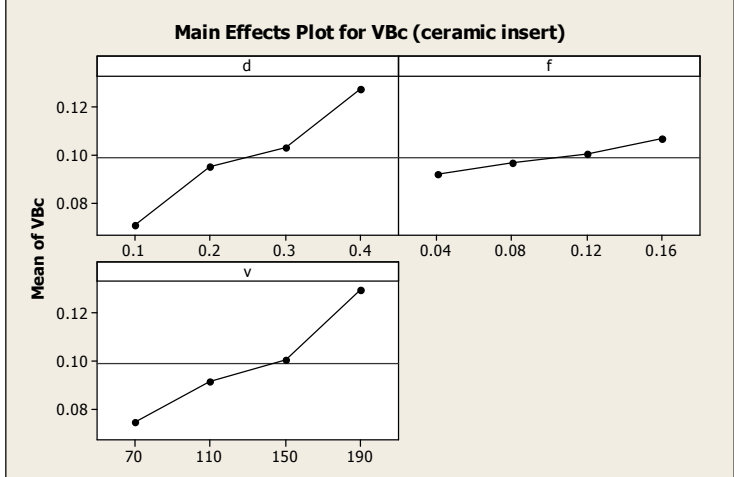

Fig. 3. Main effect plot of flank wear

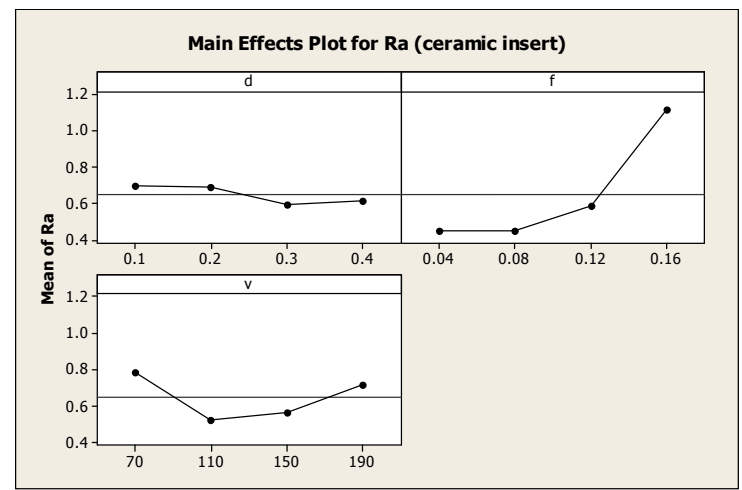

Fig.4. Main effect plot of surface roughness

From the test results and main effects plot (Fig. 3 and 4), it is revealed that flank wear increases with increase of depth of cut, feed and cutting speed. However the effect of depth of cut and cutting speed is higher compared to feed. The surface roughness increases with increase of feed drastically. The effect of depth of cut on surface roughness is marginal. The surface roughness decreases with rise of cutting speed up to $110 \mathrm{~m} / \mathrm{min}$ and then increases with increase of cutting speed from $150 \mathrm{~m} / \mathrm{min}$ to $190 \mathrm{~m} / \mathrm{min}$. From the main effect plot, it gives the uncertainty of level of process parameters that is to be chosen for hard machining as all the lower level of process parameters gives rise to lower flank wear of insert. However, depth of cut of level 3, feed of level 1 and cutting speed of level 2 yields lower surface roughness values. As both the responses are equally important because tool wear affects surface quality to a greater extent. Therefore, simultaneous optimization of both responses is essentially required to obtain the decision on both the quality characteristics in hard turning environment.

\section{Optimization methodology using grey relational analysis}

In multi-response problem, the influence and relationship between different parameters are complex and not clear. This is termed as grey which signifies poor and uncertain information. This proposed 
methodology (grey relational analysis) analyzes this complicated uncertainty among the multiresponses in a given system and optimize it with the help of grey relational grade. Therefore a multiresponse optimization problem is reduced to a single response optimization problem called single relational grade.

\section{Step-1}

The data is first to be normalized because of avoiding different units and to reduce the variability. It is essentially required since the variation of one data differs from other data. A suitable value is derived from the original value to make the array between 0 to 1 (Noorul Haq et al., 2008). In general, it is a method of converting the original data to a comparable data. If the response is to be minimized, then smaller-the-better characteristics is intended for normalization to scale it into an acceptable range by the following formula.

$$
x_{i}^{*}(k)=\frac{\max x_{i}(k)-x_{i}(k)}{\max x_{i}(k)-\min x_{i}(k)}
$$

where, $i=1, \ldots, m ; k=1, \ldots, n$., $m$ is the number of experimental data and $\mathrm{n}$ is the number of responses. $\mathrm{x}_{\mathrm{i}}(\mathrm{k})$ denotes the original sequence, $x_{i}{ }^{*}(k)$ denotes the sequence after the data preprocessing, $\max \mathrm{x}_{\mathrm{i}}(\mathrm{k})$ denotes the largest value of $\mathrm{x}_{\mathrm{i}}(\mathrm{k})$, min $\mathrm{x}_{\mathrm{i}}(\mathrm{k})$ denotes the smallest value of $\mathrm{x}_{\mathrm{i}}(\mathrm{k})$, and $\mathrm{x}$ is the desired value (Tosun \& Pihtili, 2010).

\section{Step-2}

Next step is to calculate grey relational coefficient, $\xi \mathrm{i}(\mathrm{k})$ from the normalized values by the following formula as follows

$$
\xi_{i}(k)=\frac{\Delta_{\min }+\xi \Delta_{\max }}{\Delta_{o i}(k)+\xi \Delta_{\max }},
$$

where, $\Delta_{0 \mathrm{i}}$ is the deviation sequence of the reference sequence and the comparability sequence and $\Delta_{0 i}=\| x_{0}(k)-x_{i}(k \|$

where $x_{0}(k)$ implies the reference sequence and $\mathrm{x}_{\mathrm{i}}(\mathrm{k})$ termed as comparability sequence. $\Delta_{\min }$ and $\Delta_{\max }$ are the minimum and maximum values of the absolute differences $\left(\Delta_{0 i}\right)$ of all comparing sequences. $\zeta$ is distinguishing or identification coefficient and the range is between 0 to 1 . Usually, the value of $\zeta$ is taken as 0.5 .

\section{Step-3}

To find out the grey relational grade (GRG) as follows

$$
\gamma_{i}=\frac{1}{n} \sum_{k=1}^{n} \xi_{i}(k)
$$

where, $\gamma_{i}$ is the required grey relational grade for ith experiment and $n=$ number of response characteristics. The grey relational grade represents the level of correlation between the reference sequence and the comparability sequence and is the overall representative of all the quality characteristics (Noorul Haq et al., 2008). Thus the multi-response optimization problem is converted into single response optimization problem through grey relational analysis coupled with Taguchi approach.

\section{Step-4}

Then an optimal level of process parameters is determined using higher grey relational grade that indicates the better product quality. To obtain this, average grade values for each level of process 
parameter is to be find out which can be shown as mean response table. From, mean response table, higher values of average grade values is chosen as optimal parametric combination for multi-responses.

\section{Step-5}

After optimal combination is find out, the next step is to perform the analysis of variance (ANOVA) for judging the significant parameters affecting the multi-responses at $95 \%$ confidence level and thus giving important information on the experimental data. As the effect of each parameter on multiresponse cannot be assessed by Taguchi method, thus the ANOVA analysis will be helpful to find out the percentage of contribution to identify the effects. The procedure of ANOVA is to separate out the total variability of the response (sum of squared deviations about the grand mean) into each parameter contributions and error (Datta et al., 2008). The P-value (probability of significance) is generally calculated based on F value or Fisher's F- ratio to get the information of significance on the selected response if its value is less than 0.05 . The degrees of freedom (DF) are required to evaluate the mean square (MS) and measure the availability of independent information to evaluate sum of squares (SS). In an ANOVA analysis, mean square deviation and F-value is calculated by $\mathrm{MS}=\mathrm{SS} / \mathrm{DF}$ and $\mathrm{F}=\mathrm{MS}$ for a source parameter/MS for the error.

\section{Step-6}

After optimal combination of process parameters are found out, the next step is very the improvement of grey relational grade through conducting confirmatory experiment. The predicted value of grey relational grade for optimal level can be obtained as follows,

$$
\hat{\gamma}=\gamma_{m}+\sum_{i=1}^{o}\left(\bar{\gamma}_{i}-\gamma_{m}\right)
$$

where $\gamma_{m}$ is the total mean grey relational grade, $\bar{\gamma}_{i}$ is the mean grey relational grade at the optimal level of each parameter, and $o$ is the number of the significant process parameters (Sahoo \& Sahoo, 2013).

\section{Implementation of methodology to find multi-response parametric optimization}

\section{Step-1}

The experimental data have been normalized for both flank wear and surface roughness using Eq. (1) and presented in Table 2 called grey relational generations.

Table 2

Grey relational generation values

\begin{tabular}{ccc}
\hline Run No. & VBc & Ra \\
\cline { 2 - 3 } & Smaller-the-better & Smaller-the-better \\
\hline Ideal sequence & 1 & 1 \\
1 & 1.000 & 0.277 \\
2 & 0.878 & 0.911 \\
3 & 0.827 & 0.743 \\
4 & 0.612 & 0.178 \\
5 & 0.816 & 0.931 \\
6 & 0.959 & 0.772 \\
7 & 0.214 & 0.356 \\
8 & 0.337 & 0.079 \\
9 & 0.622 & 1.000 \\
10 & 0.092 & 0.614 \\
11 & 0.786 & 0.703 \\
12 & 0.490 & 0.208 \\
13 & 0.000 & 0.881 \\
14 & 0.327 & 0.812 \\
16 & 0.276 & 0.752 \\
\hline
\end{tabular}


Step-2

From the normalized data set of Table 2, grey relational coefficients have been computed using equation 2. The value of distinguishing coefficient is taken as 0.5 as equal weighting has been given to both quality characteristics. The results are shown in Table 3.

Step-3

Next, grey relational grade (GRG) has been found out using Equation 3 from the results of grey relational coefficients. The result of GRG is presented in Table 3. This result is utilized for optimizing the multi-responses as it is converted to a single grade.

Table 3

Grey relational coefficient and grey relational grade values

\begin{tabular}{|c|c|c|c|c|c|c|}
\hline Run & Evaluation of $\Delta_{0 \mathrm{i}}$ & & Grey relati & cient & GRG & Rank \\
\hline & $\mathrm{VBc}$ & $\mathrm{Ra}$ & $\mathrm{VBc}$ & $\mathrm{Ra}$ & & \\
\hline Ideal sequence & 1 & 1 & 1 & 1 & & \\
\hline 1 & 0.000 & 0.723 & 1.000 & 0.409 & 0.704 & 5 \\
\hline 2 & 0.122 & 0.089 & 0.803 & 0.849 & 0.826 & 1 \\
\hline 3 & 0.173 & 0.257 & 0.742 & 0.660 & 0.701 & 6 \\
\hline 4 & 0.388 & 0.822 & 0.563 & 0.378 & 0.471 & 11 \\
\hline 5 & 0.184 & 0.069 & 0.731 & 0.878 & 0.805 & 3 \\
\hline 6 & 0.041 & 0.228 & 0.925 & 0.687 & 0.806 & 2 \\
\hline 7 & 0.786 & 0.644 & 0.389 & 0.437 & 0.413 & 14 \\
\hline 8 & 0.663 & 0.921 & 0.430 & 0.352 & 0.391 & 16 \\
\hline 9 & 0.378 & 0.000 & 0.570 & 1.000 & 0.785 & 4 \\
\hline 10 & 0.908 & 0.386 & 0.355 & 0.564 & 0.460 & 12 \\
\hline 11 & 0.214 & 0.297 & 0.700 & 0.627 & 0.664 & 7 \\
\hline 12 & 0.510 & 0.792 & 0.495 & 0.387 & 0.441 & 13 \\
\hline 13 & 1.000 & 0.119 & 0.333 & 0.808 & 0.571 & 9 \\
\hline 14 & 0.673 & 0.188 & 0.426 & 0.727 & 0.576 & 8 \\
\hline 15 & 0.724 & 0.248 & 0.408 & 0.669 & 0.539 & 10 \\
\hline 16 & 0.592 & 1.000 & 0.458 & 0.333 & 0.396 & 15 \\
\hline
\end{tabular}

Step-4

From the value of GRG, the effects of each process parameters at different levels are plotted and shown in Fig. 5 and mean grey relational grade is presented in Table 4. The optimal parametric combination is chosen based on higher mean grey relational grade values from Table 4 . The higher value of grey relational grade implies a stronger correlation to the reference sequence and better performance. Thus, the optimal settings for multi-responses becomes d1-f1-v2 i.e. depth of cut of $0.1 \mathrm{~mm}$, feed of 0.04 $\mathrm{mm} / \mathrm{rev}$ and cutting speed of $110 \mathrm{~m} / \mathrm{min}$ respectively. The higher values of mean grey relational grade (Fig. 5) gives the minimum values of flank wear and surface roughness. The difference of maximum and minimum values of mean GRG for turning parameters were as 0.156 for depth of cut, 0.291 for feed rate and 0.174 for cutting speed respectively (Table 4). This result indicates that the feed rate has the most influencing effect on multi-responses compared to depth of cut and cutting speed in hard turning operation. The sequence of importance of process parameters on multi-responses are feed $>$ cutting speed $>$ depth of cut.

Table 4

Main effects on mean grey relational grade.

\begin{tabular}{crrrrrr}
\hline \multirow{2}{*}{ Factors } & \multicolumn{4}{c}{ Mean Grey relational grade } & \multirow{2}{*}{ Max-Min } & Rank \\
\cline { 2 - 4 } & Level 1 & Level 2 & Level 3 & Level 4 & & \\
\hline d & 0.676 & 0.604 & 0.587 & 0.520 & 0.156 & 3 \\
f & 0.716 & 0.667 & 0.579 & 0.425 & 0.291 & 1 \\
v & 0.642 & 0.653 & 0.613 & 0.479 & 0.174 & 2 \\
\hline
\end{tabular}

Total mean grey relational grade $=0.5968$ 


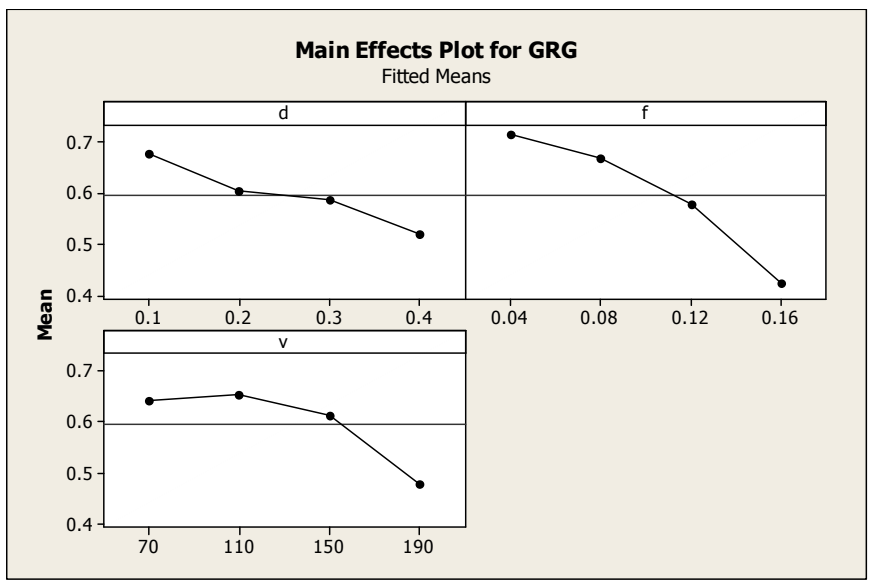

Fig.5. Main effect plot of grey relational grade

Step-5

Next, analysis of variance (ANOVA) table is formulated considering grey relational grade value which has been shown in Table 5. This table gives the significance of process parameters on multi-responses. From the ANOVA table, it is revealed that feed is the significant process parameters affecting multiresponses as its p-value is less than 0.05 at $95 \%$ confidence level. Cutting speed and depth of cut does not show any significance on both responses simultaneously.

\section{Table 5}

Results of ANOVA on grey relational grade.

\begin{tabular}{cccccccc}
\hline Source & DF & Seq SS & Adj SS & Adj MS & F & P & Remarks \\
\hline d & 3 & 0.0486 & 0.0486 & 0.0162 & 1.65 & 0.275 & Insignificant \\
f & 3 & 0.1964 & 0.1964 & 0.0654 & 6.67 & 0.024 & Significant \\
v & 3 & 0.0777 & 0.0777 & 0.0259 & 2.64 & 0.144 & Insignificant \\
Error & 6 & 0.0589 & 0.0589 & 0.0098 & & & \\
\hline Total & 15 & 0.3816 & & & & & \\
\hline
\end{tabular}

Step-6

Confirmation runs are conducted to identify the improvement of grey relational grade from initial parameter setting to the optimal parameters obtained in hard machining of AISI 52100 steel using ceramic insert. The predicted GRG can be found out using equation 4 . The grey relational grade at optimal setting becomes 0.7048 which is close to predicted value i.e. 0.8514 . From confirmation run (Table 6), it is revealed that the grey relation grade of both responses such as flank wear and surface roughness are significantly improved (0.2918) through setting of optimal parametric combination. From the above analysis, the parameters are optimized and minimum values of flank wear and surface roughness are found out in hard turning through grey relational analysis based on Taguchi approach.

Table 6

Confirmation experiment

\begin{tabular}{cccc}
\hline & Initial factor setting & \multicolumn{2}{c}{ Optimal cutting factors } \\
\cline { 3 - 4 } & & Prediction & Experiment \\
\hline Level & $\mathrm{d} 2-\mathrm{f} 3-\mathrm{v} 4$ & $\mathrm{~d} 1-\mathrm{f} 1-\mathrm{v} 2$ \\
$\mathrm{VBc}$ & 0.131 & & 0.059 \\
$\mathrm{Ra}$ & 0.87 & 0.8514 & 0.72 \\
\hline Grey relational grade & 0.413 & & 0.7048 \\
\hline Improvement in GRG $=0.2918$ & & \\
\hline
\end{tabular}




\section{Mathematical model}

Multiple regression model has been developed for both responses such as flank wear (VBc) and surface roughness (Ra) at 95\% confidence level considering cutting speed (v), feed (f) and depth of cut (d) as input parameters. The model adequacy has been checked by evaluating its determination coefficients $\left(R^{2}\right)$ value. The more is the $R^{2}$ value i.e. when approaches or close to one, the greater is the significance of model. From the experimental results, first order and second order mathematical models for flank wear and surface roughness are presented in equation 1,2, 3 and 4 along with their $\mathrm{R}^{2}$ value respectively.

First order model

$$
\begin{array}{ll}
V B c=-0.0133+0.1777 d+0.1181 f+0.0004 v & R^{2}=87.9 \% \\
R a=0.2588-0.3525 d+5.3187 f-0.0004 v & R^{2}=54.2 \%
\end{array}
$$

Second order model

$$
\begin{array}{lr}
V B c=0.0893-0.2623 d-0.3301 f-0.0003 v-0.0062 d^{2}+0.2734 f^{2}+0.00 v^{2}+2.1221 d f & R^{2}=96.5 \% \\
+0.0018 d v+0.0001 f v & \\
R a=3.3068-6.381 d-23.6001 f-0.024 v+0.6875 d^{2}+83.2031 f^{2}+0.0001 v^{2}+34.6875 & R^{2}=96.9 \% \\
d f+0.0218 d v+0.0428 f v &
\end{array}
$$

First order regression model shows very less determination coefficient values particularly for surface roughness which is $54.2 \%$. However, second order model presented higher $\mathrm{R}^{2}$ value which is close to 1. It represents best fit of the model and model is said to be statistically significant and adequate. Again, Figs. (4-5) show the comparison of experimental values and predicted values from the second order model. The figure clearly indicates that the predicted values are very close to the experimental values. Thus the developed second order model indicates good correlations between the experimental and predicted results. This comparison result shows that the developed second order model sufficiently predicts the expected results prior to experiment in hard turning of AISI 52100 steel and can be safely implemented.

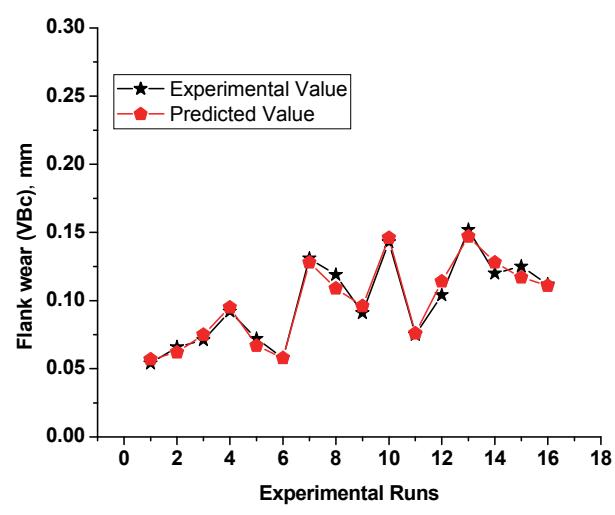

Fig. 4. Experimental vs. predicted values of flank wear

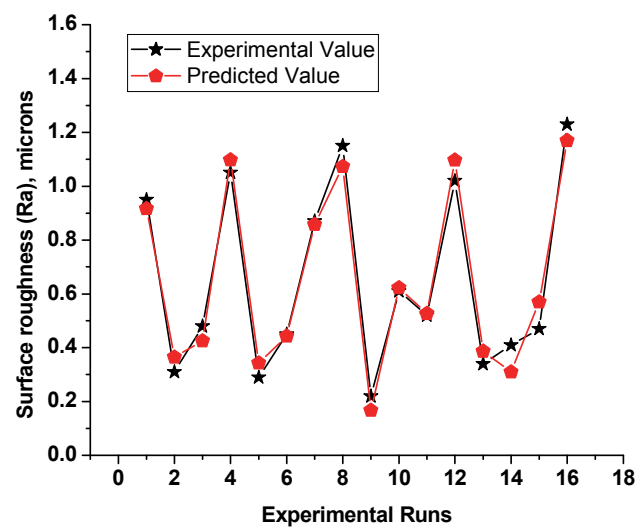

Fig. 5. Experimental vs. predicted values of surface roughness 


\section{Conclusions}

This paper presents the findings of decision making multi-criteria optimization of process parameters in hard turning of AISI 52100 steel using ceramic insert under dry environment through grey relational analysis combination with orthogonal array of Taguchi approach. The second order mathematical model has also been developed for selection of appropriate process parameters and their outcomes prior to experimentation. Based on the analysis, following conclusions are drawn.

$>$ Mixed ceramic inserts yields the values of flank wear and surface roughness less than criterion limit of $0.3 \mathrm{~mm}$ and 1.6 microns respectively in all experimental runs and can be successfully implemented in hard turning operation of hardened AISI 52100 steel.

$>$ The optimal parametric settings for multi-responses becomes d1-f1-v2 i.e. depth of cut of 0.1 $\mathrm{mm}$, feed of $0.04 \mathrm{~mm} / \mathrm{rev}$ and cutting speed of $110 \mathrm{~m} / \mathrm{min}$ respectively.

$>$ From the ANOVA table, feed rate is the most significant controlled process parameter influencing multi-responses at 95\% confidence level in hard turning operation as a case study when minimization of flank wear and surface roughness are concerned. Other parameters such as cutting speed and depth of cut does not show any significance on responses.

$>$ The grey relation grade is significantly improved (0.2918) through setting of optimal parametric combination. Thus, the results of parametric optimization can be implemented in machining industries to reduce the manufacturing cost and enhances the machining efficiency.

$>$ Second order mathematical model presented higher $\mathrm{R}^{2}$ value and represents best fit of the model and adequate compared to first order model. Model indicates good correlations between the experimental and predicted results.

$>$ The proposed grey-based Taguchi methodology has been proved to be efficient for solving multi-attribute decision making problem as a case study in hard machining environment.

\section{Acknowledgements}

Authors would like to acknowledge Central Tool Room \& Training Centre (CTTC), Bhubaneswar and School of Mechanical Engineering, KIIT University, Bhubaneswar, Odisha, India for providing their facilities to perform the experimental and measurement work. We are also delighted for constructive comments on earlier version of this paper.

\section{References}

Aggarwal, A., Singh, H., Kumar, P., \& Singh, M. (2008). Multicharacteristic optimisation of CNC turned parts using principal component analysis.International Journal of Machining and Machinability of Materials, 3(1-2), 208-223.

Asokan, P., Saravanan, R., \& Vijayakumar, K. (2003). Machining parameters optimisation for turning cylindrical stock into a continuous finished profile using genetic algorithm (GA) and simulated annealing (SA). The International Journal of Advanced Manufacturing Technology, 21(1), 1-9.

Bhuyan, R., \& Routara, B. (2016). Optimization the machining parameters by using VIKOR and Entropy Weight method during EDM process of Al-18\% SiCp Metal matrix composite. Decision Science Letters, 5(2), 269-282.

Choudhury, I. A., \& El-Baradie, M. A. (1997). Surface roughness prediction in the turning of highstrength steel by factorial design of experiments.Journal of Materials Processing Technology, 67(1), 55-61.

Chinchanikar, S., \& Choudhury, S.K. (2013). Wear behaviors of single-layer and multi-layer coated carbide inserts in high speed machining of hardened AISI 4340 steel. Journal of Mechanical Science and Technology, 27 (5), 1451-1459. 
Das, S. \& Chattopadhyay, A.B. (2003) Application of the analytic hierarchy process for estimating the state of tool wear. International Journal of Machine Tools \& Manufacture, 43, 1-6.

Datta, S., Bandyopadhyay, A., \& Pal, P. K. (2008). Slag recycling in submerged arc welding and its influence on weld quality leading to parametric optimization. The International Journal of Advanced Manufacturing Technology, 39(3-4), 229-238.

Davim, J. P. (2001). A note on the determination of optimal cutting conditions for surface finish obtained in turning using design of experiments.Journal of materials processing technology, 116(2), 305-308.

Davim, J. P., Gaitonde, V. N., \& Karnik, S. R. (2008). Investigations into the effect of cutting conditions on surface roughness in turning of free machining steel by ANN models. Journal of materials processing technology, 205(1), 16-23.

Dey, S., \& Chakraborty, S. (2016). A study on the machinability of some metal alloys using grey TOPSIS method. Decision Science Letters, 5(1), 31-44.

Lin, C.L. (2004). Use of the Taguchi Method and Grey Relational Analysis to optimize turning operations with multiple performance characteristics. Materials \& Manufacturing processes, 19 (2), 209-220.

Nalbant, M., Gökkaya, H., \& Sur, G. (2007). Application of Taguchi method in the optimization of cutting parameters for surface roughness in turning.Materials \& design, 28(4), 1379-1385.

Natarajan, U., Periasamy, V. M., \& Saravanan, R. (2007). Application of particle swarm optimisation in artificial neural network for the prediction of tool life. The International Journal of Advanced Manufacturing Technology,31(9-10), 871-876.

Haq, A. N., Marimuthu, P., \& Jeyapaul, R. (2008). Multi response optimization of machining parameters of drilling $\mathrm{Al} / \mathrm{SiC}$ metal matrix composite using grey relational analysis in the Taguchi method. The International Journal of Advanced Manufacturing Technology, 37(3-4), 250-255.

Haq, A. N., Marimuthu, P., \& Jeyapaul, R. (2008). Multi response optimization of machining parameters of drilling $\mathrm{Al} / \mathrm{SiC}$ metal matrix composite using grey relational analysis in the Taguchi method. The International Journal of Advanced Manufacturing Technology, 37(3-4), 250-255.

Noordin, M. Y., Venkatesh, V. C., Sharif, S., Elting, S., \& Abdullah, A. (2004). Application of response surface methodology in describing the performance of coated carbide tools when turning AISI 1045 steel. Journal of Materials Processing Technology, 145(1), 46-58.

Pal, S., Malviya, S. K., Pal, S. K., \& Samantaray, A. K. (2009). Optimization of quality characteristics parameters in a pulsed metal inert gas welding process using grey-based Taguchi method. The International Journal of Advanced Manufacturing Technology, 44(11-12), 1250-1260.

Palanikumar, K. (2008). Application of Taguchi and response surface methodologies for surface roughness in machining glass fiber reinforced plastics by PCD tooling. The International Journal of Advanced Manufacturing Technology, 36(1-2), 19-27.

Sahoo, A. K., Pradhan, S., \& Rout, A. K. (2013). Development and machinability assessment in turning $\mathrm{Al} / \mathrm{SiCp}$-metal matrix composite with multilayer coated carbide insert using Taguchi and statistical techniques.Archives of civil and mechanical engineering, 13(1), 27-35.

Sahoo, A., Orra, K., \& Routra, B. (2013). Application of response surface methodology on investigating flank wear in machining hardened steel using PVD TiN coated mixed ceramic insert. International Journal of Industrial Engineering Computations, 4(4), 469-478.

Sahoo, A. K., \& Sahoo, B. (2013). Performance studies of multilayer hard surface coatings (TiN/TiCN/ $/ \mathrm{Al}_{2} \mathrm{O}_{3} / \mathrm{TiN}$ ) of indexable carbide inserts in hard machining: Part-II (RSM, grey relational and techno economical approach).Measurement, 46(8), 2868-2884.

Sargade, V. G., Nipanikar, S. R., \& Meshram, S. M. (2016). Analysis of surface roughness and cutting force during turning of Ti6A14V ELI in dry environment. International Journal of Industrial Engineering Computations, 7(2), 257.

Tosun, N., \& Pihtili, H. (2010). Gray relational analysis of performance characteristics in MQL milling of $7075 \mathrm{Al}$ alloy. The International Journal of Advanced Manufacturing Technology, 46(5-8), 509515. 
Tzeng, C. J., Lin, Y. H., Yang, Y. K., \& Jeng, M. C. (2009). Optimization of turning operations with multiple performance characteristics using the Taguchi method and Grey relational analysis. Journal of materials processing technology, 209(6), 2753-2759. 